\title{
Development of Exhaust Leak Detector Device for Automotive Service Industry: A Prototype Design
}

\author{
Eida Nadirah Roslin", Siti Khadijah Ismail*, Mohd Zaki Bahrom, Mansor Aluidin" \\ \# Automotive Engineering Section, Universiti Kuala Lumpur, Malaysia France Institute, 43650 Selangor, Malaysia \\ E-mail:eidanadirah@unikl.edu.my, sitikhadijah@unikl.edu.my,zakibahrom@unikl.edu.my
}

${ }^{2}$ Industrial Automation Engineering Section, Universiti Kuala Lumpur, Malaysia France Institute, 43650 Selangor, Malaysia

\begin{abstract}
The exhaust system plays a vital role in removing the gaseous emissions that is being produced within the combustion chamber during fuel-air mixture activities. The exhaust system is defined as a series of chambers and pipes that starts at the engine and ends at the back of the car with the tail pipe. However if there are any leaks in the exhaust system, it provide a direct path for the emission gaseous including carbon monoxide to enter can be very dangerous as it provides a direct path for carbon monoxide and other dangerous gaseous emissions to enter the cowl vent at the base of the windshield and directly to the passenger compartment. The risk of exposure to these hazardous gaseous is also high especially during vehicle maintenance services in suspected cases of leakages to the exhaust system. The inspection of the exhaust system is done manually in most of the automotive services workshops. In this paper, accidental risks of performing these inspection jobs on a vehicle's exhaust system, performed by a technician are discussed. In order to minimize the risks to technicians or mechanics, a prototype device to detect exhaust leakage was developed using a gas sensor module and a web camera. This device was successfully operated in detecting possible leakages of the exhaust system.
\end{abstract}

Keywords — Exhaust System; Automotive Services; Leak Detector Design

\section{INTRODUCTION}

The exhaust is a set of passage or tubes that carries the emission gaseous from the exhaust port to the rear of the vehicle and discharges them into the air [1]. The gas that usually released to the exhaust pipe is Carbon Monoxide (CO), Carbon Dioxide (C02) and Nitrogen Oxide (NO). Since the exhaust pipe is used to flow certain gases, the leakage of the system will contribute to a high risk of exposure to the user. These hazardous gaseous will affect the human health such as the respiratory system. Due to this problem, the catalytic converter is designed in the system in order to prevent these emission gaseous being released into the air [1]. To prevent from any exhaust system error or problem happening, preventive maintenance and inspection must be carried out. Usually the maintenance works is done manually by a technician whereby the effected exhaust will be inspected by the technician.

During the inspection of the exhaust, the technician will be exposed to many risks especially the risk of exposure to these hazardous gaseous released by the leakage of the exhaust system. Due to this problem, in this study, a prototype design of an exhaust leak detector devise is proposed. This device is developed in order to reduce the possible risk of hazardous gaseous exposure to the technician as well as to minimize the working time in performing the maintenance task in relation to the exhaust leakage.

\section{RISKS DUE TO LEAKAGE OF EXHAUST SYSTEM TOWARDS TECHNICIAN}

The manual method used by technicians in inspecting the leakage on a vehicle's exhaust contributes to the high exposure of health and safety risk to the technician. Among the risks are effects to the respiratory system, blood system and skin cancer. The details of these risks are explained in this chapter.

\section{A. Respiratory Affect}

The carbon dioxide is one of the hazardous gases emitted from the exhaust system. The abnormal level of carbon dioxide (CO2) will contributed to serious health effects [2]. The study [2] shows that, the technicians group that have been exposed to high level of $\mathrm{C} 02$ (prolonged exposure) due to performing inspection jobs of leakage at exhaust pipe of vehicle, had experienced respiratory affect in their life term. 
On the hand, they were also exposed to the risk of problems related to adverse respiratory affects [3-4].

The eyes and respiratory tract can be irritated by the exhaust fumes [4]. Prolonged exposure to diesel fumes may lead to coughing and breathlessness. The risk of lung cancer may increase if the exposure to this type of gas continues in long term duration [5].

\section{B. Blood System}

The blood's ability to carry oxygen to body tissue (vital organ such as heart and brain) is inhibits by the presence of $\mathrm{CO}$. The oxygen will combine with $\mathrm{CO}$ when the human inhaled and thus will carry the haemoglobin of the blood to form carboxyhemoglobin $(\mathrm{COHb})$. Haemoglobin has a much higher affinity (240 times) for $\mathrm{CO}$ than oxygen (O2), therefore when the content of $\mathrm{CO}$ is higher in the environment, the technicians are metabolized with $\mathrm{CO}$ rather than $\mathrm{O} 2$ and the haemoglobin are affected and contributes to diseases related to the blood system in the human body. [6].

\section{Skin Cancer}

Skin cancer is one of the risks to the technician in the motor vehicle repair industry. Thermal burns and chemical burns in the vehicle repair industry can mostly be due to contact with hot surfaces, eg. Exhaust pipes or hot melt chemical and sudden release temperature. As a result, scarring will occur on the skin if the dermal layer of the skin is affected [7]. In some cases, mostly associated with chronic burn wound, malignant changes in the form of a majorly ulcer have occurred in areas of previously traumatized, chronically inflamed or scarred skin [7-9]

Basically, there are 3 major risks related to safety and health of technicians in performing the task of exhaust leaking inspection. Figure 1 shows the occupational risks and the effect towards the technicians.

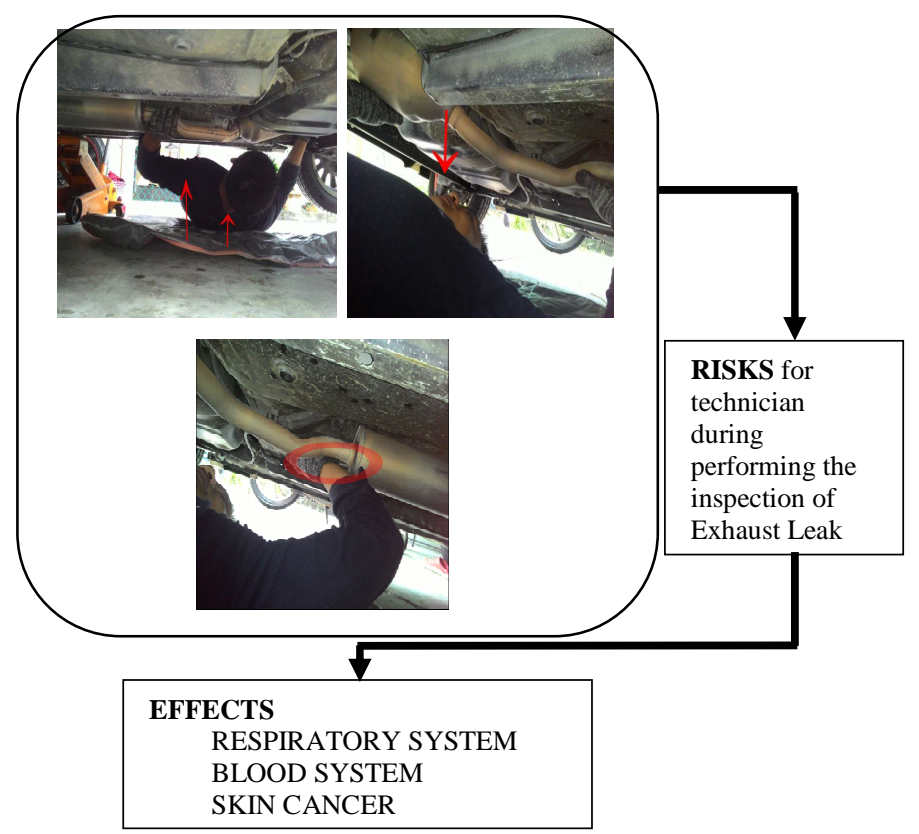

Fig. 1 Risks and Effect towards Technician in performing the inspection of exhaust Leak"

III. DeVelopment Of EXHAust LEAK Detector DeVICE
Based on the previous studies done by the researchers [10-13], a prototype of exhaust leak detector was developed in order to assists the technician in performing the inspection task of exhaust leak detection. The prototype was divided into three parts, 1-smoke detector, 2-camera and 3-remote sensor.

The smoke detector was used to sense smoke that comes out from the leakage area in the exhaust pipe. The second component is the camera. Since the smoke detector detects the presence of smoke, the camera was used to find the hole that showed the gas flowing from the leak. The third component is a remote sensor that is used as a remote device in order to hold the camera and the smoke detector under the vehicle when the inspection task was done.

The prototype was tested at the Automotive Workshop, UNIKL MFI by using a training vehicle. In this test, the function of the installed components was verified. Final testing was conducted at an Independent Workshop A. During this test, the exhaust pipes were inspected using the prototype for detection of leakage at the surface. With both of these test, the prototype was successfully operated in determining whether the exhaust leakage was a problem for a vehicle. Table 1show the list of equipment and components used in developing the prototype of Exhaust Leak Detector Device.

TABLE I

LISTS OF EQUIPMENT AND COMPONENTS USED IN DEVELOPING THE PRototype DEVICE

\begin{tabular}{|c|c|c|c|}
\hline No & & Item & Function \\
\hline 1 & $\begin{array}{l}\text { MQ-7 } \\
\text { sensor }\end{array}$ & & $\begin{array}{l}\text { A sensor for detecting the } \\
\text { existence of CO } \\
\text { concentrations in the air. } \\
\text { Can detect CO gas } \\
\text { concentration from 20- } \\
\text { 2000PPM. } \\
\text { This sensor has a high } \\
\text { sensitivity and fast response } \\
\text { time. }\end{array}$ \\
\hline 2 & Resistor & & $\begin{array}{l}\text { Resistor act to reduce } \\
\text { current flow and at the same } \\
\text { time act to lower voltage } \\
\text { level within circuit. } \\
\text { In this product, it used } 5 \\
\text { resistors with different } \\
\text { range which is } 10 \text { kilo ohm, } \\
1 \text { kilo ohm, } 22 \text { ohm, } 560 \\
\text { ohm and } 10 \text { ohm. }\end{array}$ \\
\hline 3 & Capacitor & & $\begin{array}{l}\text { A capacitor is a passive two- } \\
\text { terminal electrical } \\
\text { component used to store } \\
\text { energy electro statically in } \\
\text { an electric field. }\end{array}$ \\
\hline 4 & $\begin{array}{l}\text { Variable } \\
\text { Resistor }\end{array}$ & & $\begin{array}{l}\text { A resistor is a } \\
\text { semiconductor device used } \\
\text { to amplify and switch } \\
\text { electronic signals and } \\
\text { electrical power. } \\
\text { It is composed of } \\
\text { semiconductor material } \\
\text { with at least three terminals } \\
\text { for connection to an } \\
\text { external circuit }\end{array}$ \\
\hline
\end{tabular}




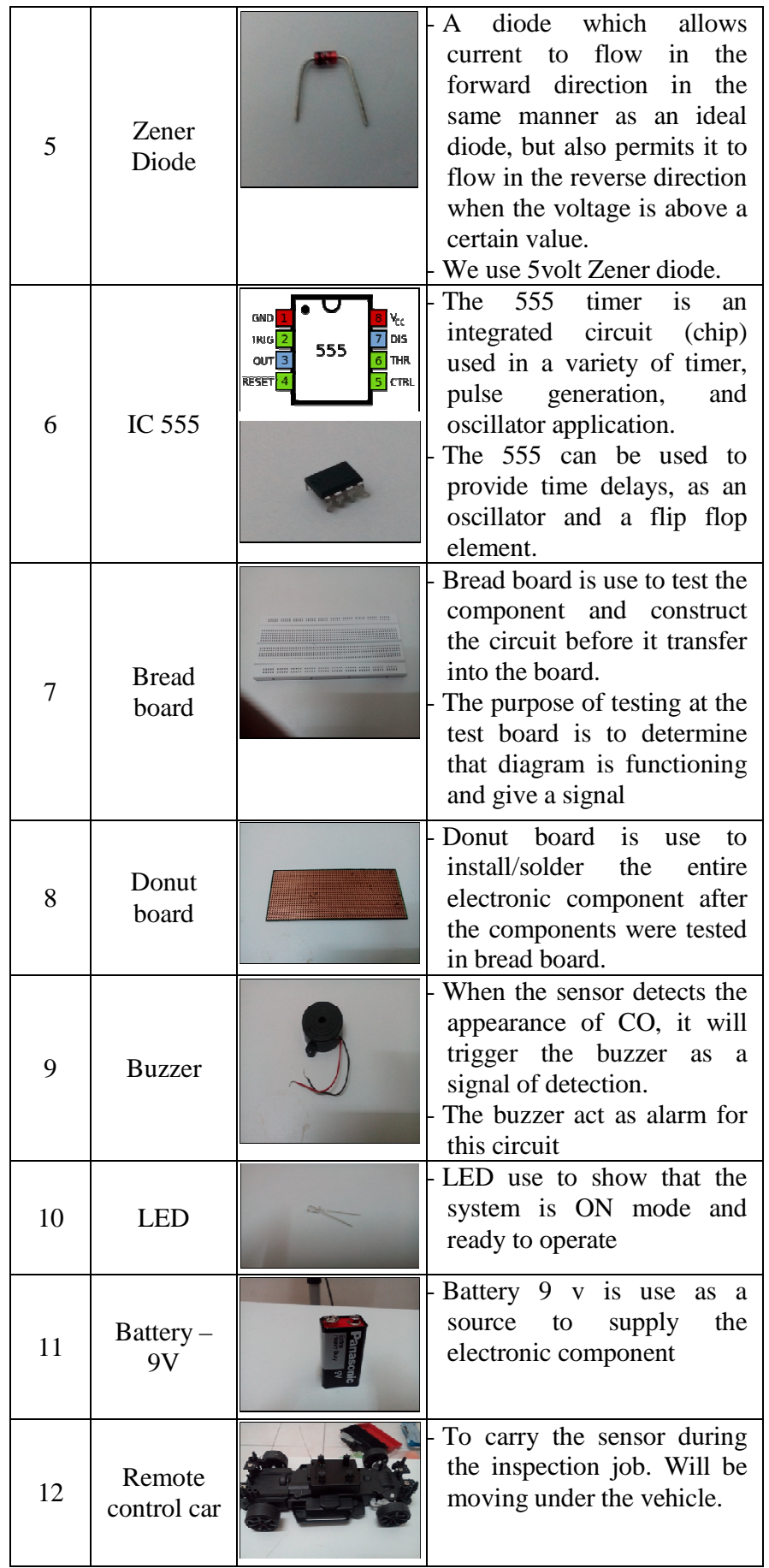

\section{A. Circuit Diagram}

Figure 2, Figure 3 and Figure 4 show the circuit diagram of exhaust leak detector device. This circuit is integrated with smoke detector and flame detector. The testing process of the components function is done using the smoke produced from motorcycle's exhaust. After all the connection of the components is well function, the final circuit is installed on the Donut board as per shown in figure 4.

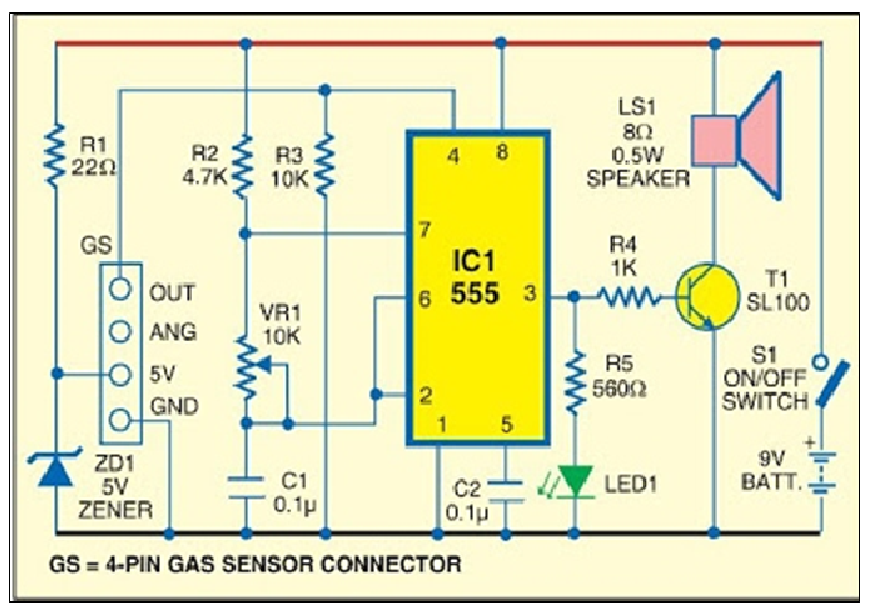

Fig. 2 "Circuit Diagram of Exhaust Leak Detector"

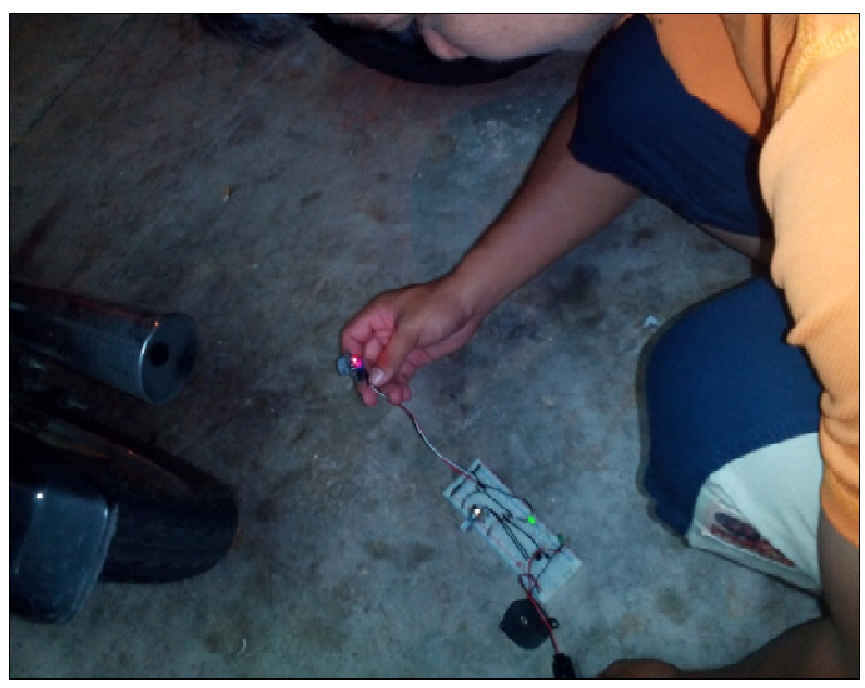

Fig. 3 "Components Installation Testing using Exhaust of Motorcycle"

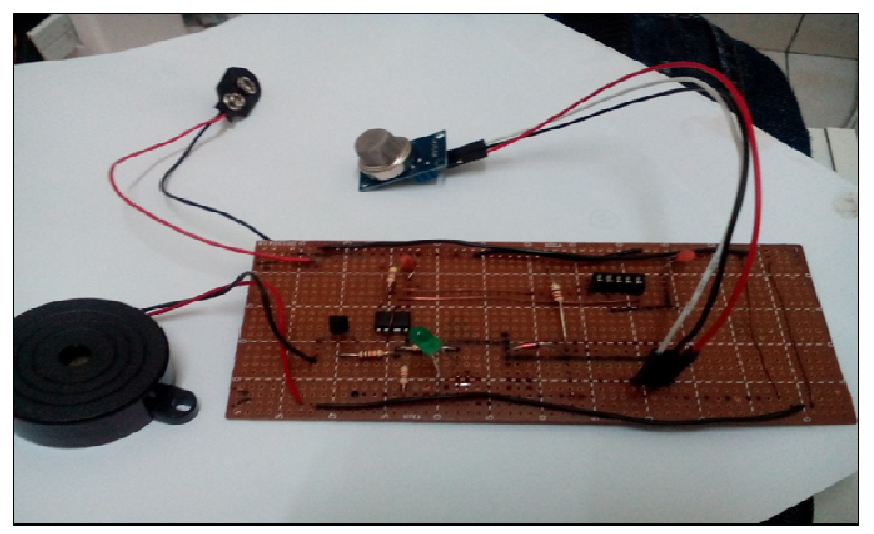

Fig. 4 "Final Components Installed on Donut Board- based on the Final Circuit Diagram"

\section{B. Exhaust Leak Detector}

After all the component was installed, the final testing of the device was done. First testing was to ensure the movability of the device under the selected vehicle. The device was allocated under the exhaust system and by using the remote control; it was moved along the exhaust pipe. 
Figure 5 shows the final installation of the exhaust leak detector device.

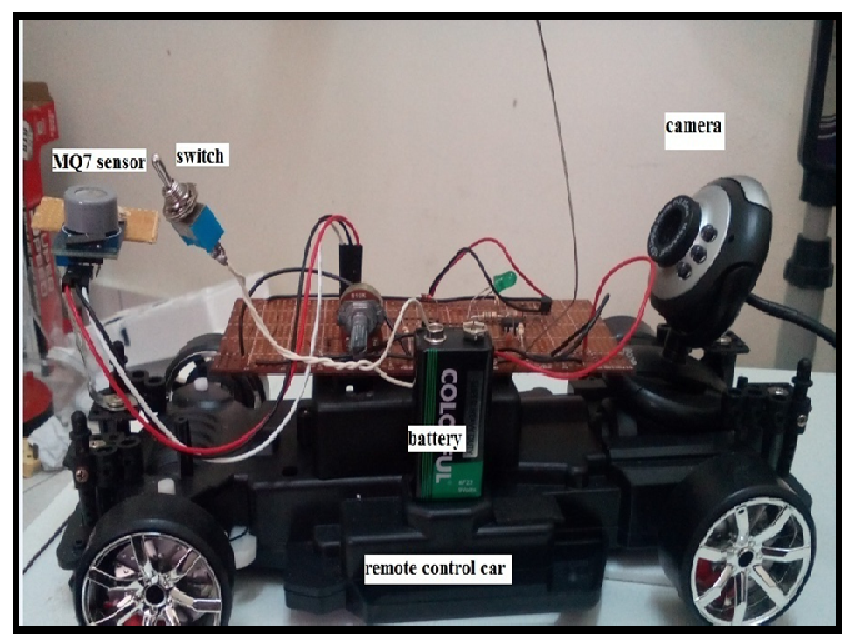

Fig. 5 Final Installation of Exhaust Leak Detector Device

Next step is to test the smoke sensor whether it can detect the present of the $\mathrm{CO}$ gas. In this test, the connection of exhaust system is loosened in order to let the emission gas from the exhaust system flow out. This was done in order to test the proper function of the device in detecting a leakage problem on the exhaust pipe system of the selected vehicle. When the engine started, the device was moved under the exhaust system and it successfully detected the leakage with the existence of the emission gas (CO) flow out from the exhaust pipe. This (CO) gas sensor detects the concentration of $\mathrm{CO}$ in the air. The sensor can detect concentrations of 20 to $2000 \mathrm{ppm}$. Resistance value of MQ-7 is difference to various kinds of $\mathrm{CO}$ gas concentration. So, when using this component, sensitivity adjustment is necessary. Figure 6 shows the sensor indicator of detecting the gas released from the exhaust pipe.

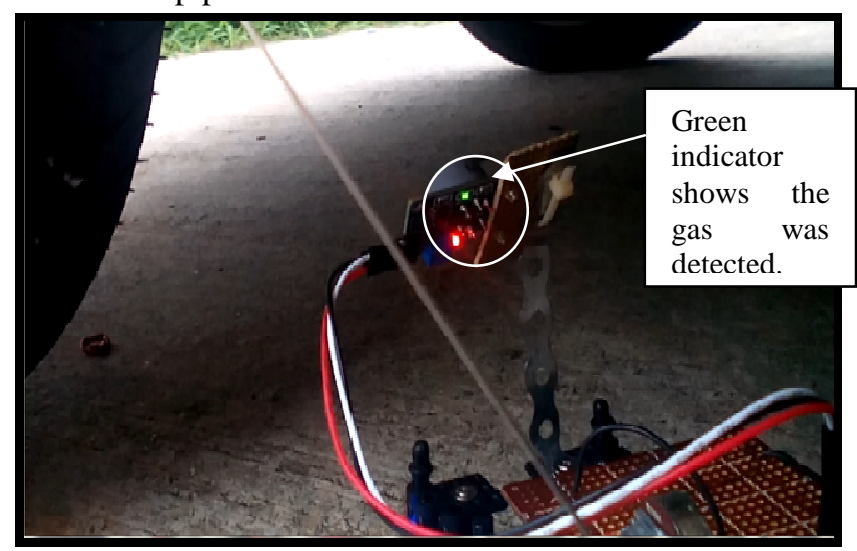

Fig. 6 Sensor Indicator (Green Light) Detect the Leakage from Exhaust Pipe

\section{CONCLUSIONS AND RECOMMENDATION}

The prototype of exhaust leak detector was successfully developed in order to ease the technicians during the inspection task of a suspected exhaust leak at an automotive workshop. The aim of this device is to decrease the job risks (safety and health) to the technicians related to hazardous gases produced by incomplete combustion. On the other hand, the device will assists the technicians in reducing the time needed in performing the particular task. To ensure the device operates accurately, the selection of sensors needs to be done thoroughly as the main function of the device relies on the accuracy of the sensors being selected.

It is recommended that in future, besides using a microcontroller for the system, the ARDUINO programming can be used in order to integrate all the main equipment (sensor and camera).

\section{ACKNOWLEDGMENT}

This project was funded by University Kuala Lumpur Malaysia France Institute. Authors would like to thank all staff at Automotive Engineering Section for their valuable helps and sharing expertise in completing this project.

\section{REFERENCES}

[1] K.K.Srinivasan, P.J.Mago, \& S.R. Krishnan, "Analysis of Exhaust Waste Heat Recovery from a Dual Fuel Low Temperature Combustion Engine using an Organic Rankine Cycle”, Energy, vol 35, issue 6, pp. 2387-2399, Jun 2010.

[2] A. Arora, W. L. Bivens, D.L. Krahn \& R.N. Peterson, "Leak Detection Method and Apparatus for an Exhaust Purification System”, Patent US 5709080 A, Jan 1998.

[3] M. Rattermana, L. Shena, D. Klotzkinb \& I. Papautsky, "Carbon Dioxide Luminescent Sensor based on a CMOS Image Array", Sensors and Actuators B: Chemical, vol 198, pp. 1-6, July 2014.

[4] S. Torp \& B.E. Moen, "The Effects of Occupational Health and Safety Management on Work Environment and Health: A Prospective Study", Applied Ergonomics, vol 37, Issue 6, pp. 775783, November 2006.

[5] Xiaobing Pang \& Yujing Mu, "Characteristics of Carbonyl Compounds in Public Vehicles of Beijing City: Concentrations, Sources, and Personal Exposures", Atmospheric Environment, vol 41, issue 9, pp. 1819-1824, March, 2007.

[6] J. A. Raub, M. M. Nolf, N. B. Hampson \& S.R. Thom, "Carbon Monoxide Poisoning - A Public Health Perspective", Toxicology, vol 145, issue 1, pp. 1-14, April 2000.

[7] Ferdousi, Jahan Ara; Ananto, Samiul Ehsan; Ahmed, \& Md. Naveed, "Development of Carbon Monoxide Detecting Device using MQ-7 Sensor along with its Statistical Analysis", BRAC University, Aug 2014.

[8] Susan Ford, "Health and Safety In The Motor Vehicle Repair", Retrieved from http: ///www.hse.gov/ (Accessed Date 16.04.2015)

[9] Stanley T. Omaye, "Metabolic Modulation of Carbon Monoxide Toxicity", Toxicology, vol 180, Issue 2, pp. 139-150, November 2002.

[10] Bertrand Seigeot, "Method and Apparatus for Detecting Leaks in Heat Exchangers for Motor Vehicles", Patent US 6314794 B1, Nov 2001.

[11] R.A. Ziskind and M.B. Rogozen, "Carbon Monoxide Intrusion into Sustained-use Vehicles", Environmental International, vol 5, issue 2, pp. 109-123, 1981.

[12] R. B. Devlin, W. F. McDonnell, R. Mann, S. Becker, D. E. House, D. Schreinemachers, \& H. S. Koren, "Exposure of Humans to Ambient Levels of Ozone for 6.6 Hours Causes Cellular and Biochemical Changes in the Lung", American Journal of Respiratory Cell and Molecular Biology, Vol. 4, No. 1, pp. 72-81, 1991.

[13] Erica Weir, "Diesel Exhaust, School Buses and Children's Health", CMAJ, vol 167, no. 5, Sept 2002. 